\title{
Temporal variation of the Shinmoe-dake crater in the 2011 eruption revealed by spaceborne SAR observations
}

\author{
Taku Ozawa and Tomofumi Kozono \\ National Research Institute for Earth Science and Disaster Prevention, Japan \\ (Received November 5, 2012; Revised April 5, 2013; Accepted May 6, 2013; Online published July 8, 2013)
}

\begin{abstract}
SAR observations to investigate the 2011 Shinmoe-dake eruption were carried out using several SAR satellites. We detected temporal variations of the Shinmoe-dake crater in the SAR images. A convex shape appeared in the PALSAR image acquired on January 27 , but it is unclear whether this shape indicates a lava dome. A larger convex shape that does indicate a lava dome could be identified in SAR images acquired after that, and it seems to have grown progressively. Estimating topography so that the simulated intensity image corresponds to the acquired one, we estimated that the lava dome grew from the morning of January 29 until January 31 with a constant effusion rate of $88.7 \mathrm{~m}^{3} / \mathrm{sec}$. The lava volume of 15 million $\mathrm{m}^{3}$ estimated from the TerraSAR-X image of February 1 was consistent with that of airborne SAR observation within $20 \%$ of its volume. From the estimated lava effusion rate and lava-covered area, we estimated that lava viscosity was less than $2.1 \mathrm{GPa} \cdot \mathrm{s}$, suggesting the potential to form a lava flow. Furthermore, we corrected the foreshortening distortion using the estimated topography and suggested that the lava effusion point was around the crater lake.
\end{abstract}

Key words: Shinmoe-dake, Kirishima, eruption, SAR, lava, volume, viscosity, effusion rate.

\section{Introduction}

Shinmoe-dake is a stratovolcano that is included in the Kirishima volcanic group located in the southern Kyushu district of Japan (Fig. 1). The crater at the summit (1421 $\mathrm{m}$ asl) has a diameter of $750 \mathrm{~m}$ and a crater lake in the bottom. According to historical documents, large magmatic eruptions occurred in 1716 and 1717, and phreatic or phreatomagmatic eruptions have occurred repeatedly since then (Imura and Kobayashi, 1991).

On January 19, 2011, a phreatic eruption occurred in the Shinmoe-dake crater, and eruption activity began. Three sub-Plinian eruptions occurred on January 26 and 27, and rapid crustal deformation associated with each eruption was detected by tiltmeters operated by the National Research Institute for Earth Science and Disaster Prevention (NIED) (Fig. 2). Lava effusion to the summit crater began on January 27 or 28 , and continuous tilt change started at approximately the same time. Crustal deformation related to this eruption activity was observed by InSAR (Miyagi et al., 2013), tiltmeter, and GPS observations (Ueda et al., 2013), and inflation in the pre-eruption period, deflation in the coeruption period, and re-inflation in the post-eruption period were detected. Miyagi et al. (2013) indicated that most of deformation can be explained by the inflation/deflation source located about $5 \mathrm{~km}$ west-northwest of the Shinmoedake at depth of $7.5 \mathrm{~km}$ bsl. Tilt changes associated with the sub-Plinian eruptions and lava effusion were directed toward the source location. Thereafter, Vulcanian eruptions

Copyright (c) The Society of Geomagnetism and Earth, Planetary and Space Sciences (SGEPSS); The Seismological Society of Japan; The Volcanological Society of Japan; The Geodetic Society of Japan; The Japanese Society for Planetary Sciences; TERRAPUB.

doi:10.5047/eps.2013.05.004 occurred intermittently. The number of eruptions decreased with time, and no eruption has been observed since a small eruption on September 7, 2011.

As mentioned above, lava appeared in the summit crater in this eruption activity. The Earthquake Research Institute (ERI) of Tokyo University carried out visual observation from a helicopter on the morning of January 28 and found that the crater lake had disappeared and a lava dome had appeared (Nakada et al., 2011). Visual observation from an airplane by the Japan Maritime Self-Defense Force on January 31 confirmed that most of the crater was covered by lava. After that, the crater surface changed with time due to numerous Vulcanian eruptions and tephra accumulation. Such variation of the crater is important information for assessing volcanic activity and researching eruption mechanisms. However, observation of the interior of the crater in the visible band is generally difficult because plumes and clouds cover the crater. Furthermore, an airborne observation involves risk when eruption activity is high.

Spaceborne synthetic aperture radar (SAR) is a useful tool for such volcano observation. SAR is an active sensor that transmits a radar pulse from an antenna, receives a returned pulse from the land surface, and obtains land-surface images with a spatial resolution on the order of several meters. Since a radar wave penetrates plumes and clouds, SAR can observe the land surface regardless of plumes, weather, and sunlight. Furthermore, spaceborne observation has the advantage of being able to avoid risk with volcanic eruption. Because the SAR image effectively reflects topography, it is suitable for observing topographic change.

Frequent SAR observations by several satellites were conducted from January 27 to investigate eruption activity. In this paper, we discuss temporal variations of the crater 

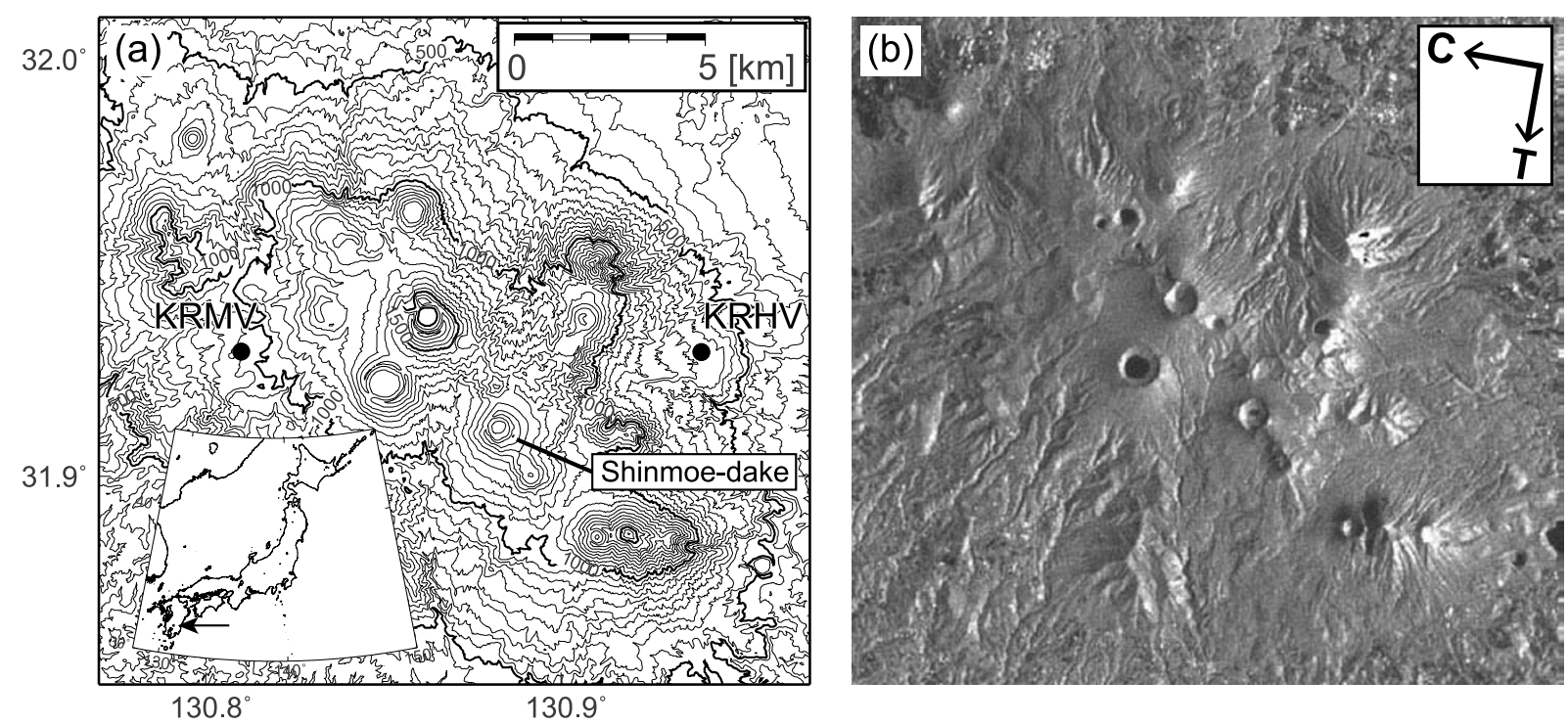

Fig. 1. (a) Map around Shinmoe-dake, in the Kirishima Volcano Group. Solid circles denote locations of NIED volcano observation sites (KRMV: Manzen, KRHV: Hinamori). Topographic contours are depicted using the digital ellipsoidal height model used in this study. Inset indicates the location of this map. (b) The PALSAR image acquired on January 18, 2011. Arrows indicate along-track (T) and cross-track (C) directions for the satellite that acquired this image.

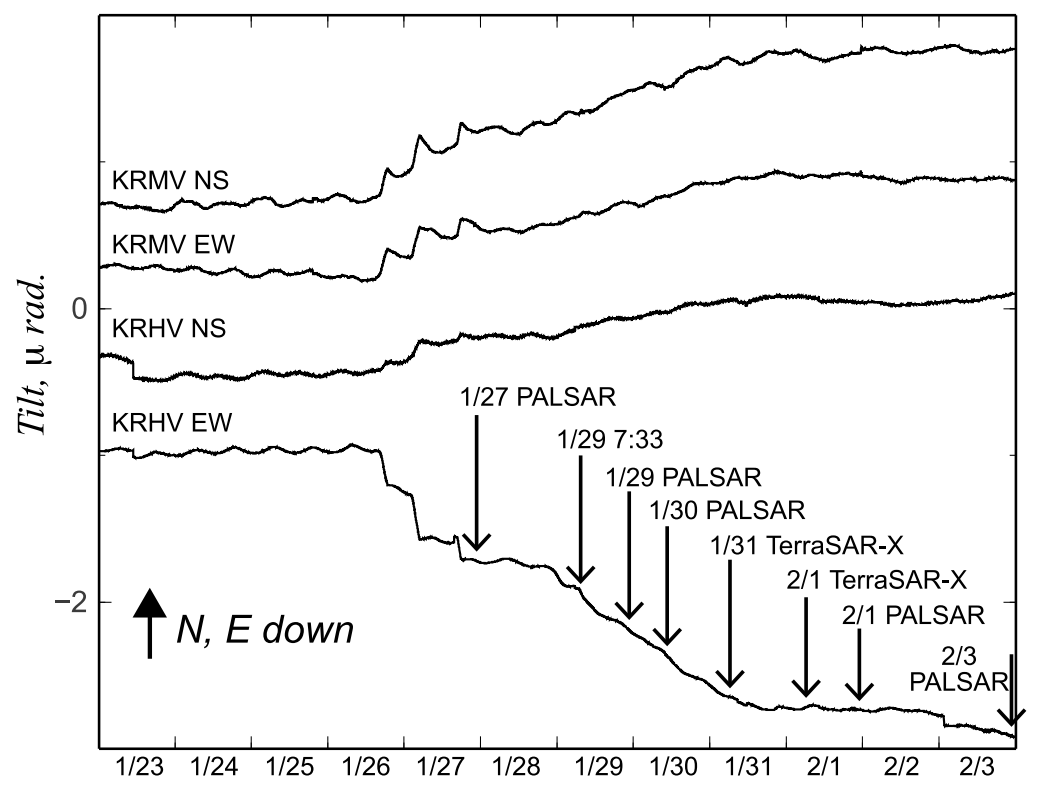

Fig. 2. Tilt change from January 23, 2011, to February 3 observed at KRMV (Manzen) and KRHV (Hinamori). Arrows indicate SAR observation times and the time of $\mathrm{x}$-intercept in the estimation of the lava effusion rate.

surface identified using these SAR images. Furthermore, we developed a simple method for rough quantitative estimation of topography from one SAR image and confirmed growth of the lava dome in the crater using this method. Based on the results, we discuss the viscosity of lava in the crater.

\section{SAR Images}

In response to the January 19 eruption, the Volcano Working Group, a special project evaluating the Advanced Land Observing Satellite (ALOS) for disaster mitigation coordinated by the Japan Meteorological Agency (JMA) and the Japan Aerospace Exploration Agency (JAXA), proposed emergent observations by ALOS to investigate erup- tion activity. ALOS has two optical sensors (AVNIR-2 and PRISM) and an L-band (23.6 cm wavelength) SAR sensor (PALSAR); observations using these sensors were carried out based on this proposal. However, the inside of the crater could not be observed using the optical sensors in January because plumes and clouds covered the crater. Therefore, this paper focuses on only SAR observations. Although the orbit recurrence time of ALOS is 46 days, PALSAR observations of Shinmoe-dake were frequently carried out from many orbit tracks by different radar incidence angles (Table 1 shows parameters for SAR data used in this study). PALSAR raw data (level 1.0) was processed to generate a single-look complex image using the GAMMA SAR processor (Wegmüller and Werner, 1997). We also requested 
Table 1. SAR data used in this study.

\begin{tabular}{|c|c|c|c|c|c|c|}
\hline & Date & Time (JST) & Satellite & Inc. angle & $\mathrm{A} / \mathrm{D}^{1}$ & Path (ALOS) \\
\hline $\mathrm{a}$ & $2011 / 1 / 18$ & $10: 44$ & ALOS & 39 & $\mathrm{D}$ & 73 \\
\hline $\mathrm{b}$ & $2011 / 1 / 27$ & $22: 53$ & ALOS & 50 & A & 428 \\
\hline $\mathrm{c}$ & $2011 / 1 / 29$ & $22: 36$ & ALOS & 24 & A & 420 \\
\hline $\mathrm{d}$ & $2011 / 1 / 30$ & $10: 39$ & ALOS & 44 & $\mathrm{D}$ & 71 \\
\hline $\mathrm{e}$ & $2011 / 1 / 31$ & $6: 28$ & TerraSAR-X & 21 & $\mathrm{D}$ & - \\
\hline $\mathrm{f}$ & $2011 / 2 / 1$ & $6: 11$ & TerraSAR-X & 52 & $\mathrm{D}$ & - \\
\hline $\mathrm{g}$ & $2011 / 2 / 1$ & $22: 59$ & ALOS & 55 & A & 431 \\
\hline $\mathrm{h}$ & $2011 / 2 / 3$ & $22: 24$ & ALOS & 35 & A & 423 \\
\hline $\mathrm{i}$ & $2011 / 2 / 4$ & $10: 45$ & ALOS & 35 & $\mathrm{D}$ & 74 \\
\hline $\mathrm{j}$ & $2011 / 2 / 6$ & $10: 28$ & ALOS & 55 & $\mathrm{D}$ & 66 \\
\hline $\mathrm{k}$ & $2011 / 2 / 7$ & $18: 10$ & TerraSAR-X & 31 & A & - \\
\hline 1 & $2011 / 2 / 8$ & $22: 48$ & ALOS & 44 & A & 426 \\
\hline $\mathrm{m}$ & $2011 / 2 / 9$ & $10: 52$ & ALOS & 24 & $\mathrm{D}$ & 77 \\
\hline $\mathrm{n}$ & $2011 / 2 / 11$ & $10: 35$ & ALOS & 50 & $\mathrm{D}$ & 69 \\
\hline o & $2011 / 2 / 12$ & $6: 11$ & TerraSAR-X & 52 & $\mathrm{D}$ & - \\
\hline $\mathrm{p}$ & $2011 / 2 / 15$ & $22: 38$ & ALOS & 29 & A & 421 \\
\hline $\mathrm{q}$ & $2011 / 2 / 18$ & $10: 23$ & ALOS & 58 & $\mathrm{D}$ & 64 \\
\hline $\mathrm{r}$ & $2011 / 2 / 18$ & $18: 10$ & TerraSAR-X & 31 & A & - \\
\hline $\mathrm{s}$ & $2011 / 2 / 18$ & $23: 01$ & ALOS & 58 & A & 432 \\
\hline $\mathrm{t}$ & $2011 / 2 / 20$ & $22: 44$ & ALOS & 39 & A & 424 \\
\hline $\mathrm{u}$ & $2011 / 2 / 23$ & $6: 11$ & TerraSAR-X & 31 & $\mathrm{D}$ & - \\
\hline $\mathrm{v}$ & $2011 / 2 / 23$ & $10: 30$ & ALOS & 54 & $\mathrm{D}$ & 67 \\
\hline w & $2011 / 2 / 25$ & $22: 50$ & ALOS & 47 & A & 427 \\
\hline $\mathrm{x}$ & $2011 / 2 / 26$ & $6: 11$ & RADARSAT-2 & 52 & $\mathrm{D}$ & - \\
\hline $\mathrm{y}$ & $2011 / 2 / 28$ & $10: 36$ & ALOS & 47 & $\mathrm{D}$ & 70 \\
\hline $\mathrm{z}$ & $2011 / 3 / 3$ & $18: 25$ & RADARSAT-2 & 46 & A & - \\
\hline aa & $2011 / 3 / 4$ & $22: 34$ & ALOS & 32 & A & 422 \\
\hline $\mathrm{bb}$ & $2011 / 3 / 5$ & $10: 43$ & ALOS & 39 & $\mathrm{D}$ & 73 \\
\hline $\mathrm{cc}$ & $2011 / 3 / 6$ & $6: 11$ & TerraSAR-X & 52 & $\mathrm{D}$ & - \\
\hline dd & $2011 / 3 / 8$ & $10: 25$ & ALOS & 57 & $\mathrm{D}$ & 65 \\
\hline ee & $2011 / 3 / 12$ & $10: 31$ & ALOS & 50 & $\mathrm{D}$ & 68 \\
\hline $\mathrm{ff}$ & $2011 / 3 / 14$ & $22: 51$ & ALOS & 50 & A & 428 \\
\hline gg & $2011 / 3 / 17$ & $6: 11$ & TerraSAR-X & 52 & $\mathrm{D}$ & - \\
\hline hh & $2011 / 3 / 17$ & $10: 38$ & ALOS & 44 & $\mathrm{D}$ & 71 \\
\hline ii & $2011 / 3 / 19$ & $22: 58$ & ALOS & 55 & A & 431 \\
\hline $\mathrm{jj}$ & $2011 / 3 / 22$ & $6: 18$ & RADARSAT-2 & 36 & $\mathrm{D}$ & - \\
\hline $\mathrm{kk}$ & $2011 / 3 / 27$ & $18: 25$ & RADARSAT-2 & 46 & A & - \\
\hline 11 & $2011 / 3 / 29$ & $10: 35$ & ALOS & 50 & $\mathrm{D}$ & 69 \\
\hline
\end{tabular}

${ }^{1} \mathrm{~A}$ and $\mathrm{D}$ indicate the ascending and descending orbit tracks, respectively.

observations by TerraSAR-X (X-band ( $3.1 \mathrm{~cm}$ wavelength) SAR) and RADARSAT-2 (C-band $(5.6 \mathrm{~cm}$ wavelength) SAR) and obtained SAR images of the Shinmoe-dake crater every few days.

In the PALSAR image acquired on January 18, a lowbackscatter intensity area was observed in the crater bottom, indicating a crater lake (Fig. 3(a)). The total reflection component of a radar wave dominates on calm water, and therefore the backscatter is weak. Such a low-backscatter intensity area was not observed in the PALSAR image on January 27 , indicating that the crater lake had disappeared. Instead, a backscatter intensity distribution that may indicate convex-shaped topography appears around the center of the crater (Fig. 3(b)). Its width in the satellite's along-track direction is $100 \mathrm{~m}$. As mentioned before, the lava dome was detected by ERI on the morning of the next day (Nakada et al., 2011). Therefore a lava dome may have already appeared half a day earlier. However, it is difficult to identify whether it is truly a lava dome because the image lacked sufficient spatial resolution. It may indicate another surface structure. Then, there is room for argument as to whether a lava dome appeared on the night of January 27. In the PALSAR image acquired on January 29, an obvious convex shape can be identified, indicating a lava dome (Fig. 3(c)). It is also seen in SAR images acquired thereafter, and the size seems to increase progressively. Furthermore, a ring shape on the lava dome was observed in TerraSAR-X images acquired on January 31 and February 1 (Figs. 3(e) and (f)). This shape must be a fold structure associated with lava effusion, and its center must be the effusion point of lava. However, the SAR image is distorted by the foreshortening effect; therefore, correction is necessary to estimate the exact size and horizontal location. Correction of this distortion requires a digital terrain model (DTM). However, existing DTMs cannot be used because this eruption activity significantly changed the topography of the crater. We 

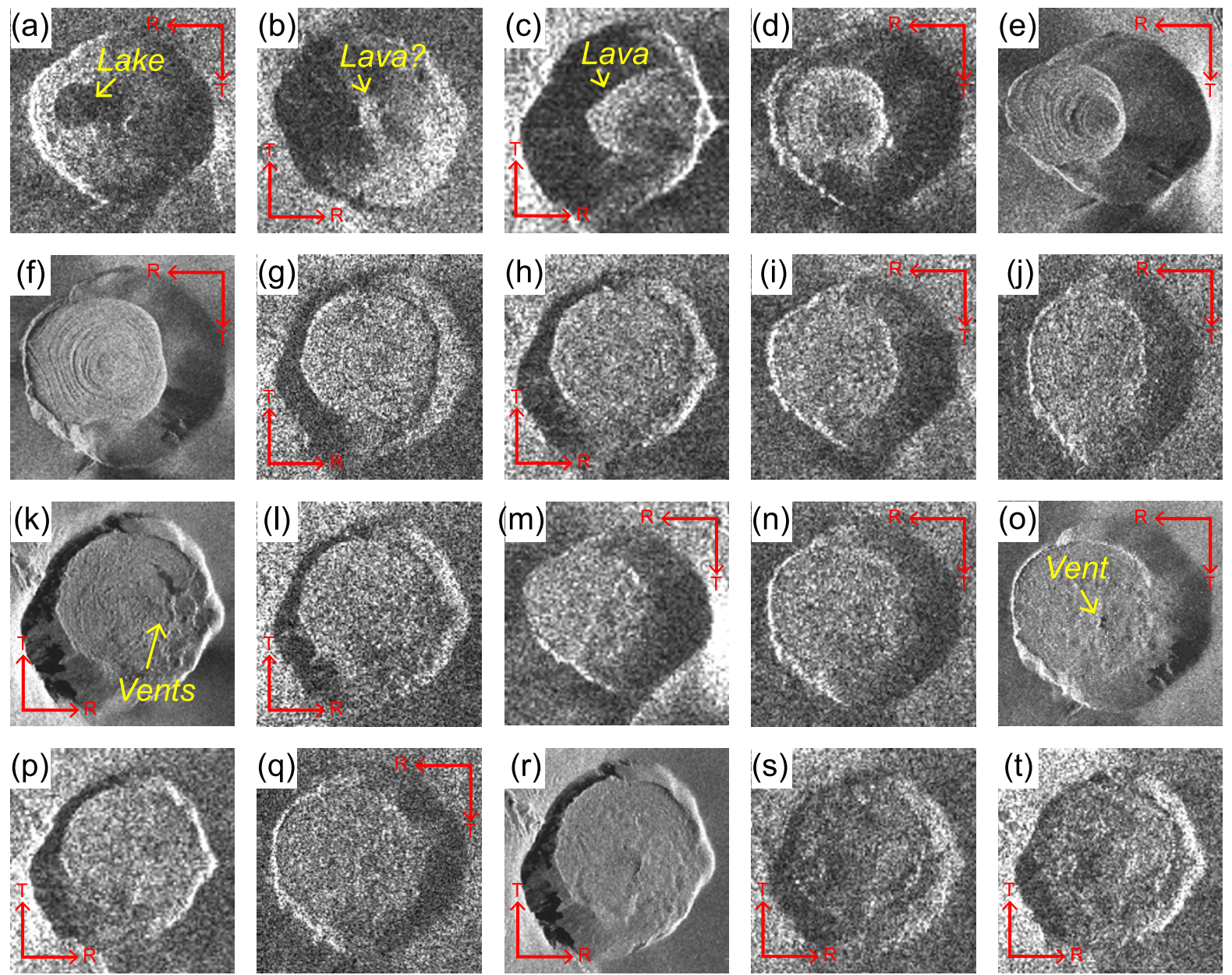

Fig. 3. SAR images around the Shinmoe-dake crater observed from January 18, 2011, to March 29. Detailed information for each image is given in Table 1. These were described in radar coordinates. Although the aspect ratios of these images were adjusted so that the ground-range and azimuth resolutions roughly correspond, the areas of the images are not exactly the same due to foreshortening distortion. Red arrows indicate along-track (T) and range $(\mathrm{R})$ directions.

address this problem in the next section.

Convex-shaped lava is also observed in PALSAR images acquired on February 1 and 3 (Figs. 3(g) and (h)), but it seems to flatten with time, probably due to gravitational deformation. Thereafter, Vulcanian eruptions occurred intermittently, and tephra accumulated in and around the crater. The shape of the lava dome became obscure on the SAR image with time. However, characteristic features on the lava surface can be identified in TerraSAR-X and RADARSAT-2 images, which have higher spatial resolution. In the TerraSAR-X image acquired on February 7, craters and cracks extending north and south appeared in the eastern part of the lava dome (Fig. 3(k)). Before this observation, Vulcanian eruptions occurred actively, and so we assume that the volcanic vents and cracks were formed by these eruptions. In the TerraSAR-X image acquired on February 12, these volcanic vents and cracks seemed to be covered by tephra, but another volcanic vent appeared in the center of the lava dome (Fig. 3(o)). It may be the volcanic vent for an explosive eruption that occurred on February 11 . In the TerraSAR-X image acquired on February 23, volcanic vents and cracks extending north and south reappeared around the eastern part of the lava dome (Fig. 3(u)), but their locations seem to differ from those of the volcanic vents observed in the TerraSAR-X image of February 7. It is necessary to correct foreshortening distortion in order to determine their exact locations, which we discuss later. No significant change was observed in the RADARSAT-2 image acquired on February 26 (Fig. 3(x)). However, a crater was observed in the RADARSAT-2 image acquired on March 3 (Fig. 3(z)). Such a crater could not be identified from the PALSAR image acquired on February 28 (Fig. 3(y)), due to insufficient spatial resolution. JAXA analyzed the TerraSAR-X image of March 1 and found a crater at the same location (Miyagi, 2013). Analyzing weather Doppler radar data, Shimbori and Fukui (2012) found an echo from an ash plume with a height of $4 \mathrm{~km}$ asl on February 28. This small crater may have been formed by its eruption. Although small changes (e.g., the appearance of small vents) were identified thereafter, no significant change was detected (Figs. 3(aa)-(11)).

\section{Estimation of the Topography in the Crater}

As mentioned in the previous section, successive images of the lava in the crater were obtained by SAR observations. We want to investigate how lava has grown. However, we cannot compare the SAR images directly because the foreshortening distortions of the SAR images differ. Cor- 

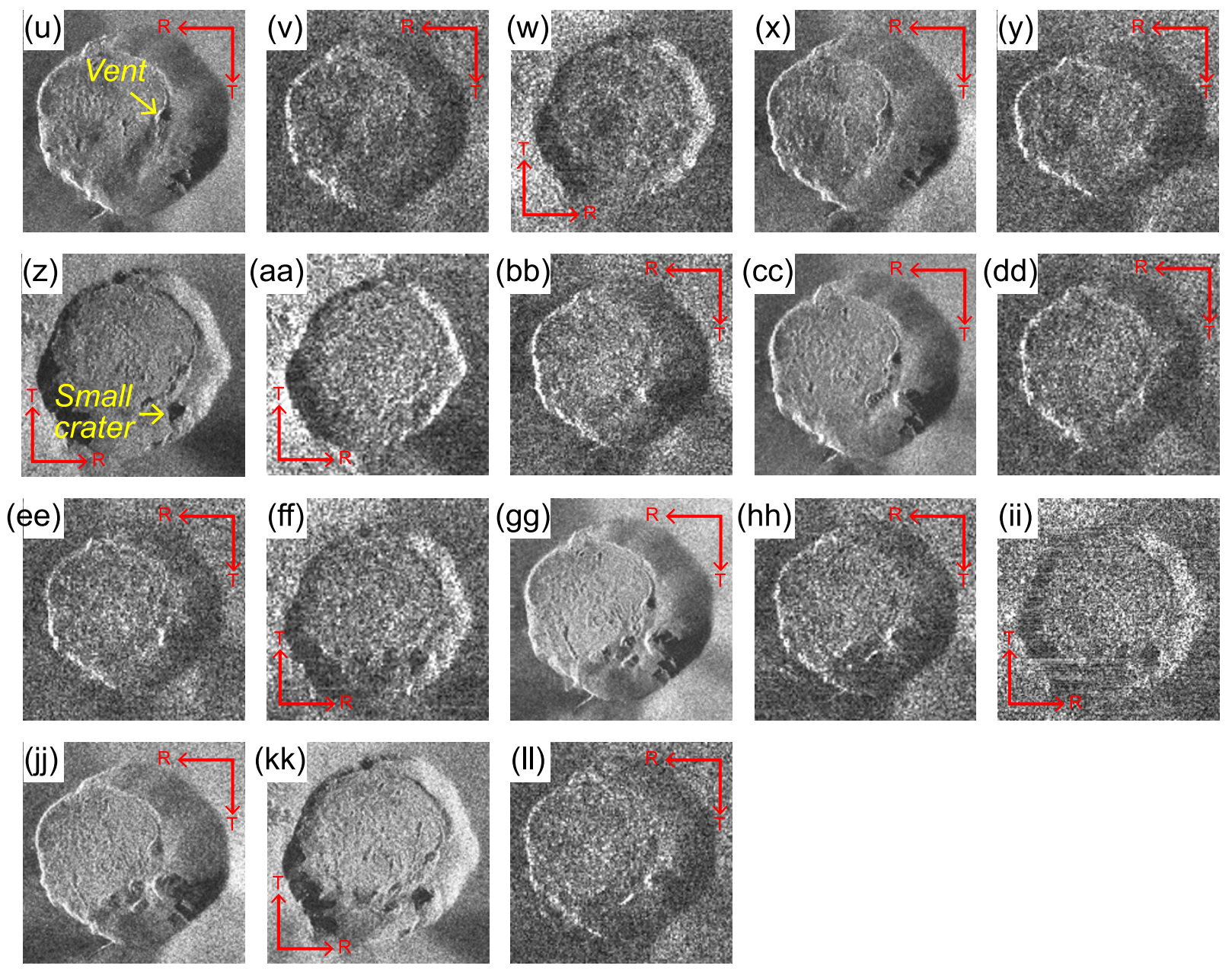

Fig. 3. (continued).

rection of such distortion requires a DTM. However, existing DTMs cannot be used because this eruption activity significantly changed the topography of the crater. Furthermore, DTM generation techniques such as repeat-pass InSAR (e.g., Li and Goldstein, 1990) and SAR stereomapping (e.g., Leberl et al., 1986) cannot be applied to a crater that rapidly changes scattering characteristics and shape. Therefore, we developed a method that roughly estimates the topography from one SAR image. We describe this method below.

In the simple simulation of backscatter, the following backscatter coefficient $\sigma_{0}$ is used:

$$
\sigma_{0}=\sigma_{m} \cos \theta,
$$

where $\sigma_{m}$ is the maximum value for the backscatter coefficient, and $\theta$ is the angle between the line-of-sight (LOS) direction and the normal direction of the local slope at the pixel (Ulaby et al., 1982). As is clear from this equation, if the LOS direction is close to the normal direction of the local slope, the backscatter intensity is strong, and vice versa. Thus, the slope of the topography strongly contributes to the backscatter intensity in an SAR image, and the SAR intensity image can be simulated using a DTM. Such a simulation is used as a general technique for connecting a SAR image to the corresponding geographical coordinates (e.g., Wegmüller, 1999). In this study, we used the GAMMA SAR processor for the simulation. The simulated image from the pre-eruption DTM corresponds well to the actual observation (Fig. 4(a)), although it differs from SAR images taken after the eruption began. Inversely, a DTM modified so that the simulated image corresponds to the observation should indicate the actual topography. Although it is difficult to estimate complex topography with this approach, a simple structure such as a lava dome can be roughly estimated, approximating the simple function in its shape. For simplicity, we assume the shape of the lava dome to be spheroidal in this study, and the parameters for the spheroid (geographical coordinates of the spheroid center, lengths of the three axes, and horizontal rotation angle of the spheroid) are estimated (Fig. 5). Only the part of a spheroid that is higher than the pre-eruption topography is adopted. We use a digital ellipsoidal height model based on the $10 \mathrm{~m}$-mesh elevation model published by the Geospatial Information Authority of Japan (GSI) and the EGM96 geoid model (Lemoine et al., 1997) as a pre-eruption DTM. The geoid height around Shinmoe-dake calculated from EGM96 is $31 \mathrm{~m}$.

Best-fit parameters were determined using the following procedure. (1) Modification of the DTM. (2) Simulation of a SAR intensity image based on the modified DTM. (3) Coregistration of the observed and simulated SAR intensity images. (4) Comparison between the observed and sim- 
(a)
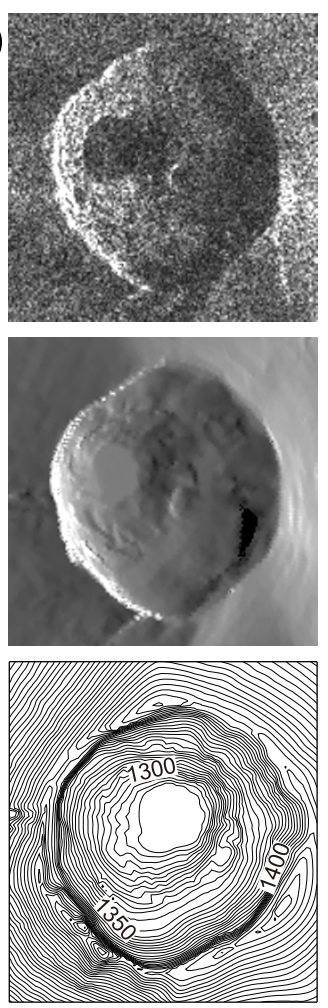

(e)
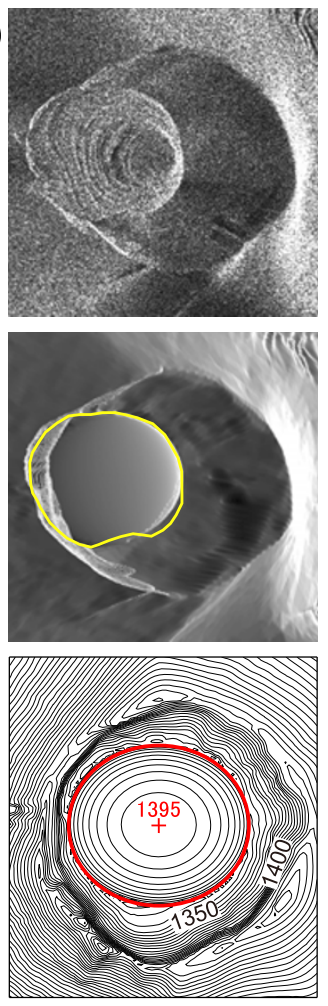

(b)
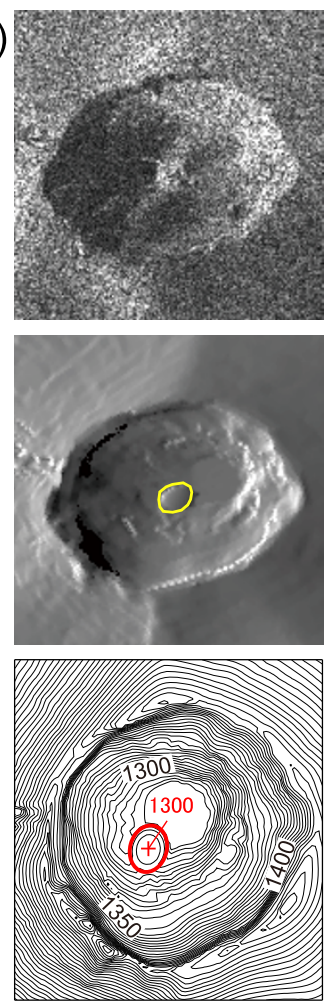

(f)
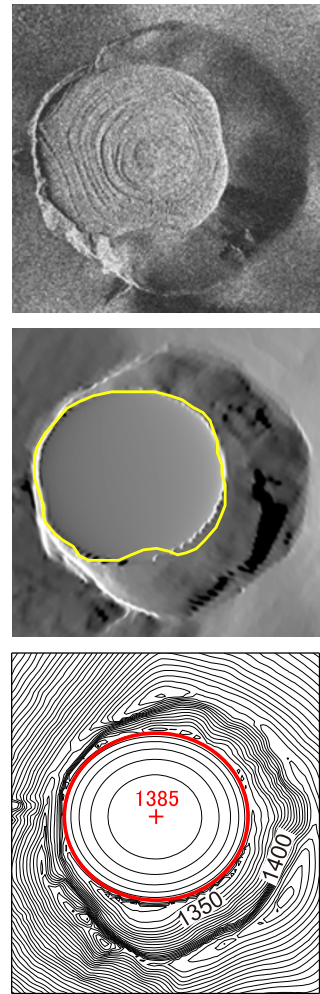

(c)
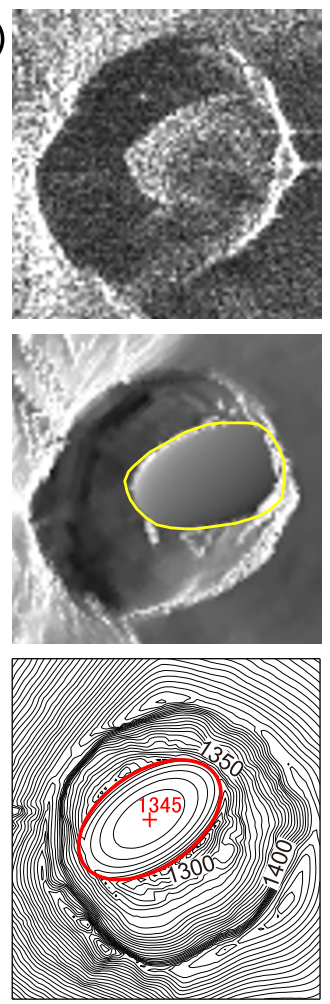

(g)
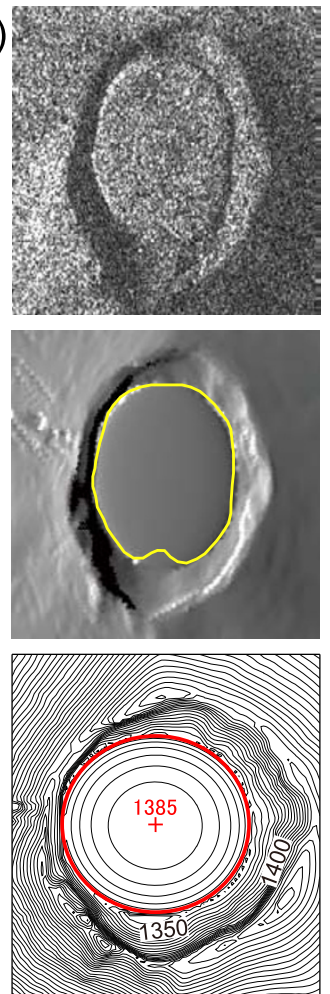

(d)
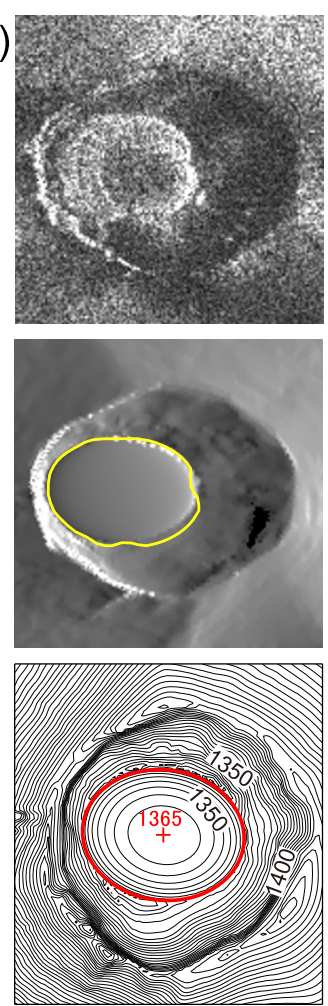

(h)
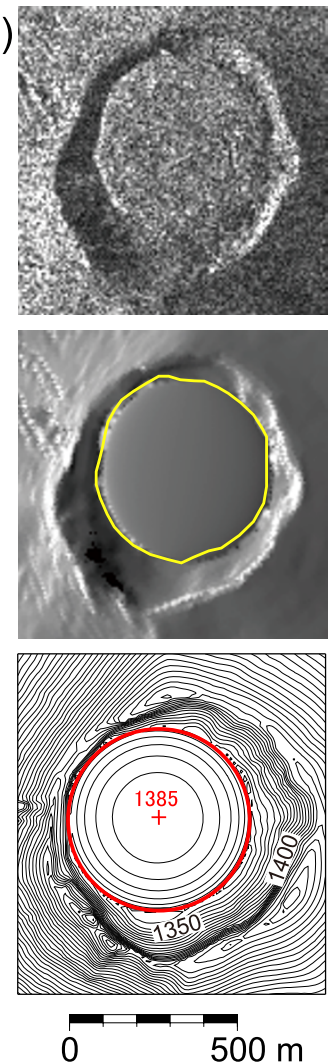

Fig. 4. Acquired image (top), simulated image (middle), and estimated topography (bottom). SAR images were described in radar coordinates; foreshortening distortion was not corrected. Topographic contours are depicted using the digital ellipsoidal height model used in this study. The yellow curve in the simulated image denotes the margin of lava dome traced in the observed image. In the estimated topography, thin curves represent contours of ellipsoidal heights, and the red circle indicates a schematic margin of lava dome. The red cross in the red circle represents the top of ellipsoid, and the attached number is its ellipsoidal height. (a) PALSAR image acquired on January 18. (b) PALSAR image acquired on January 27. (c) PALSAR image acquired on January 29. (d) PALSAR image acquired on January 30. (e) TerraSAR-X image acquired on January 31. (f) TerraSAR-X image acquired on February 1. (g) PALSAR image acquired on February 1. (h) PALSAR image acquired on February 3 . See Table 1 for observation times. 


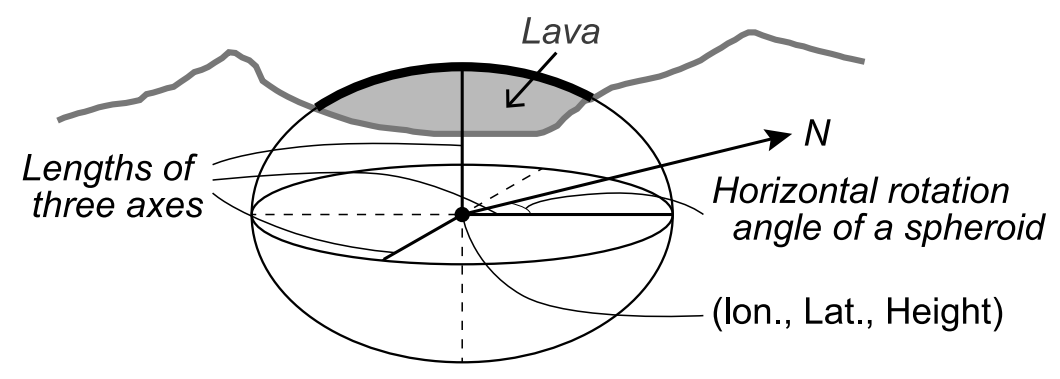

Fig. 5. Schematic diagram for the assumed shape of a lava dome.

Table 2. Estimated parameters for the crater lava.

\begin{tabular}{crccc}
\hline Date & Time & Volume $\left[10^{6} \mathrm{~m}^{3}\right]$ & Area $\left[10^{4} \mathrm{~m}^{2}\right]$ & Radius $[\mathrm{m}]$ \\
\hline $2011 / 1 / 27$ & $22: 53$ & 0.2 & 1.2 & 61.2 \\
$2011 / 1 / 29$ & $22: 36$ & 5.0 & 11.1 & 188.0 \\
$2011 / 1 / 30$ & $10: 39$ & 8.4 & 15.2 & 219.8 \\
$2011 / 1 / 31$ & $6: 28$ & 15.1 & 20.9 & 257.7 \\
$2011 / 2 / 1$ & $6: 11$ & 15.1 & 23.4 & 272.8 \\
$2011 / 2 / 1$ & $22: 59$ & 15.4 & 24.1 & 277.2 \\
$2011 / 2 / 3$ & $22: 24$ & 15.4 & 23.9 & 276.0 \\
\hline
\end{tabular}

ulated SAR intensity images. If the consistency between them is inadequate, return to (1) with different parameters for the ellipsoid equation.

In the comparisons between observed and simulated images, we used a display tool that is able to compare two SAR intensity images and is included in the GAMMA SAR processor (dis2pwr). Best-fit parameters were determined so that the margin of the lava dome and the intensity contrast on the lava surface fitted well between the observed and simulated images.

Figure 4 depicts an observed image, the corresponding simulated SAR image, and the modified topography. The stronger intensity on the lava than in the surrounding area must be due to differences in scattering characteristics, surface roughness, and permittivity. Considering such effects, the simulated images correspond to the observations. Any detailed differences must be due to a mismatch between the assumed spheroid and the actual shape. The estimated DTMs indicate that lava appeared around the southeast side of the crater lake and that the lava growth was centered there. The top of the lava dome reached a maximum of $1395 \mathrm{~m}$ (1964 $\mathrm{m}$ asl), on January 31, and the lava flattened with time thereafter. The margin of the lava dome can be identified clearly in the observed and simulated images, and their consistency is high. On the other hand, the backscatter intensity contrast is not so clear, and therefore the uncertainty in the $z$-axis length of the ellipsoid may be large. We estimated the DTM based on a TerraSAR-X image observed on the morning of February 1 (Fig. 4(f)), and GSI conducted airborne SAR observations at noon on the same day and estimated the DTM around the crater using a single-pass InSAR analysis (Shimono et al., 2011). We then compared these DTMs to consider the uncertainty. Figure 6 compares the ellipsoidal height profiles along $\mathrm{A}-\mathrm{A}^{\prime}$ and $\mathrm{B}-\mathrm{B}^{\prime}$; profiles for the airborne SAR observation were taken from the figure in Shimono et al. (2011). These are in good agreement. The lava volume was estimated based on a comparison be- tween the estimated and pre-eruption DTMs, and the resulting value for the TerraSAR-X image was 15 million $\mathrm{m}^{3}$ (Table 2). In contrast, the lava volume estimated from airborne SAR observations was 18 million $\mathrm{m}^{3}$. The difference corresponds to approximately $20 \%$ of the volume estimated in this study. Figure 7 compares backscatter intensity profiles along $\mathrm{C}-\mathrm{C}^{\prime}$, corresponding to part of the $\mathrm{A}-\mathrm{A}^{\prime}$ profile in Fig. 6; the simulated backscatter intensity is consistent with the observation. When we simulated a SAR intensity image from the DTM that added $20 \mathrm{~m}$ to the $z$-axis length of the best-fit ellipsoid (dashed curves in Fig. 6; lava volume is $120 \%$ ), the difference between it and the observation could just be identified. Based on this, we assume that allowing for $20 \%$ uncertainty is reasonable for results in this study.

\section{Discussions}

4.1 Locations of volcanic vents and cracks in the crater The location of a feature appearing in the SAR image can be calculated using the estimated topography. The convex shape in the PALSAR image of January 27 was estimated to be on the southwest side of the crater lake. Other centers for estimated spheroids were determined to be in the crater lake (solid circles in Fig. 8). Furthermore, the centers of the rings on the lava in the TerraSAR-X images acquired on January 31 and February 1 were also determined to be in the crater lake (solid triangles in Fig. 8). These results suggest that the lava effused from around the crater lake.

Although the topography after February 3 was not estimated in this study, airborne SAR observations conducted by GSI on February 7 indicated that the crater was flatly filled to $1340 \mathrm{~m}$ asl (1371 $\mathrm{m}$ in ellipsoidal height) by lava and tephra (Shimono et al., 2011). We assumed a flat crater bottom with an ellipsoidal height of $1371 \mathrm{~m}$ and estimated locations of features on SAR images acquired thereafter. Locations of volcanic vents and the crack extending north and south that were observed in the TerraSAR-X image of February 7 were determined to be in the area along the 

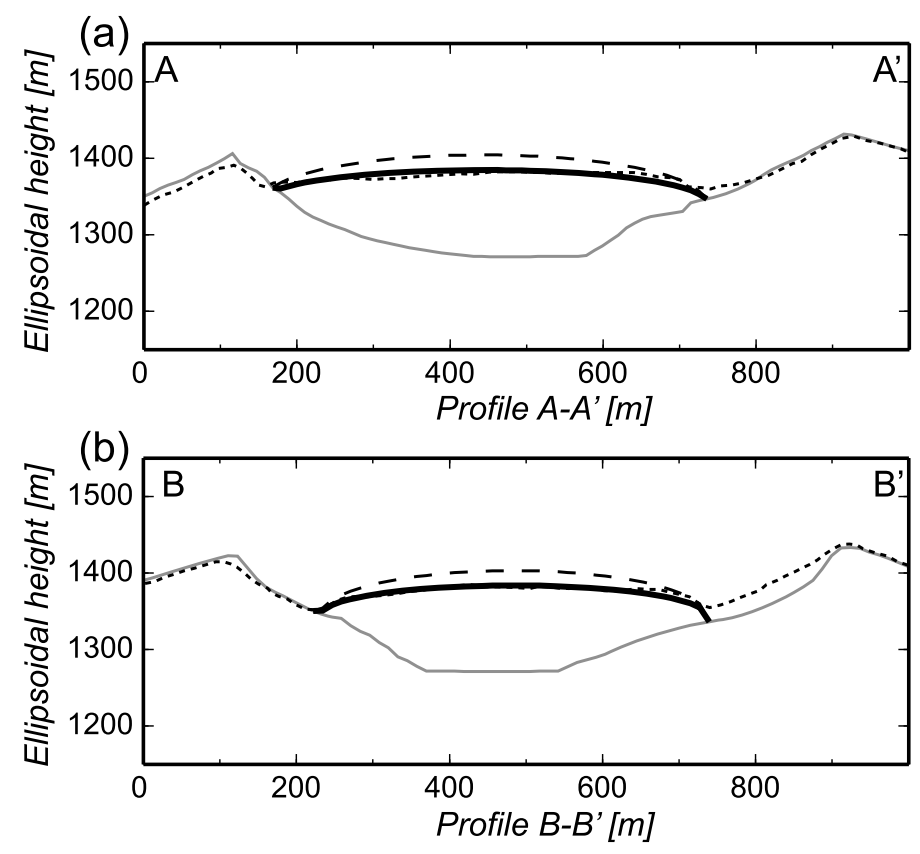

(c)

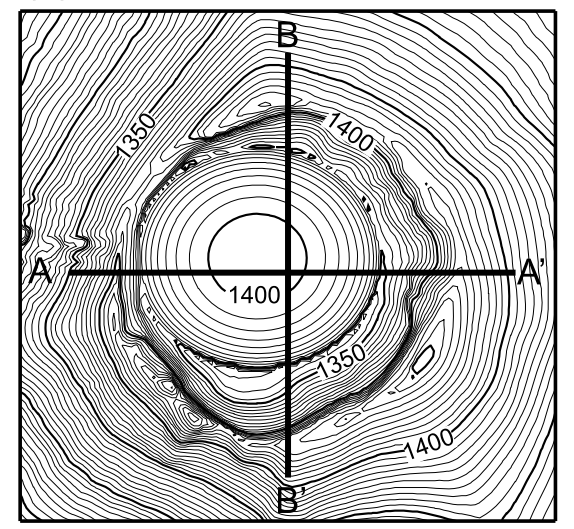

Fig. 6. Comparison between the topography estimated from the TerraSAR-X image (thick curve) and from the airborne SAR observation (dotted curve). The topography based on airborne SAR observations was taken from a figure in Shimono et al. (2011). Both observations were carried out on 1 February 2011. The thin curve represents the pre-eruption topography. The dashed curve represents the topography profile in which the top of the ellipsoid is $20 \mathrm{~m}$ higher than best-fit value, corresponding to the topography in which the lava volume is $120 \%$ of that in the best-fit topography. (a) and (b) represent profiles of the ellipsoidal height along $\mathrm{A}-\mathrm{A}^{\prime}$ and $\mathrm{B}-\mathrm{B}^{\prime}$ directions. Their locations are indicated in (c).

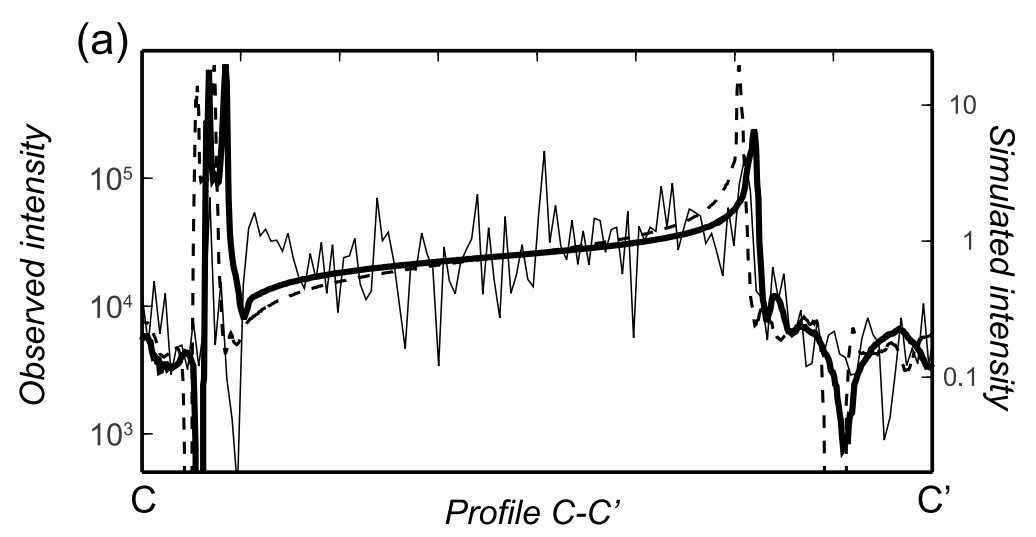

(b)

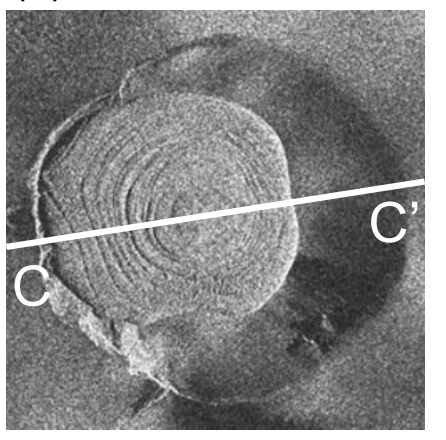

Fig. 7. (a) Comparison between the observed and simulated backscatter intensities for the TerraSAR-X image acquired on 1 February 2011 . The location of the profile is indicated in (b), corresponding to the profile for A- $\mathrm{A}^{\prime}$ in Fig. 6 . The thin line depicts the average of the observed backscatter intensity in five pixels along the profile. The thick curve represents the backscatter intensity profile for the simulated image. The dashed curve represents the intensity profile for the simulated image in which the top of the ellipsoid is $20 \mathrm{~m}$ higher than the best-fit value, corresponding to the topography in which the lava volume is $120 \%$ of that in the best-fit topography.

northeast side of the crater lake (Fig. 8). Furthermore, the location of the volcanic vent observed in the TerraSAR-X image of February 12 was determined to be in the crater lake (Fig. 8). Thus, it is suggested that eruptions occurred mainly around the crater lake until mid-February. Their locations are in the area covered by lava, indicating that eruptions during this period penetrated lava. Locations of volcanic vents and cracks observed in the TerraSAR-X image of February 23 were determined to be in the area along the eastern margin of the lava dome (Fig. 8). Furthermore, the location of the small crater in the RADARSAT-2 image of March 3 was determined to be in the area close to the southeast crater wall (Fig. 8). Thus, eruption activity from late February probably shifted to a vent in the southeast crater wall.

\subsection{Effusion rate and viscosity of crater lava}

Lava volume was estimated from comparison between the estimated and the pre-eruption DTMs. This result indicates that the volume of lava rapidly increased from January 29 to 31 and reached 15 million $\mathrm{m}^{3}$ by January 31 (Fig. 9 and Table 2). Thereafter, the increase was negligible. Even if $20 \%$ uncertainty is considered, the lava volumes of January 29,30 , and 31 seemed to increase at a constant rate. When we fitted them to a linear equation, we obtained a lava effusion rate of $88.7 \mathrm{~m}^{3} / \mathrm{sec}$ (dashed line in Fig. 9). The determination coefficient for this fitting was larger than 0.99 , suggesting that the effusion rate of lava was actually constant. Furthermore, the X-intercept was estimated on Jan- 


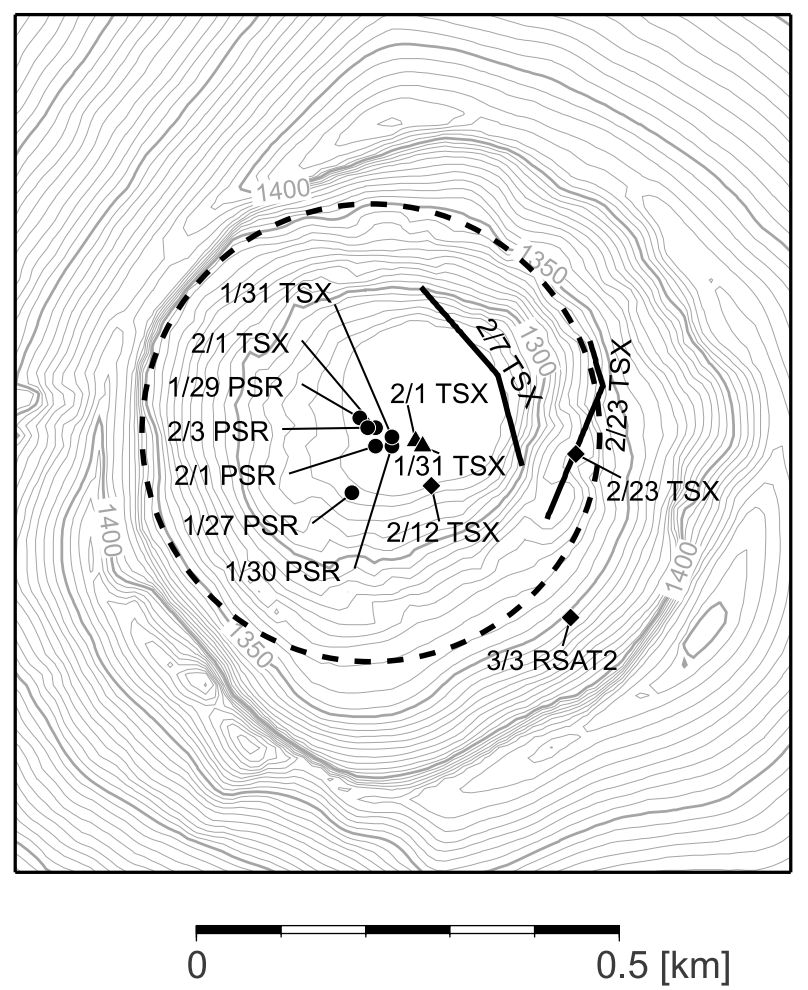

Fig. 8. Estimated locations of features on SAR images. Solid circles indicate centers of estimated lava dome. Solid triangles indicate centers of the rings that appeared on TerraSAR-X images acquired on January 31 and February 1. Solid diamonds denote locations of volcanic vents, and solid lines denote cracks. The dashed circle indicates a schematic margin of lava dome estimated from the TerraSAR-X image of February 1 . Topographic contours are depicted using the digital ellipsoidal height model used in this study.

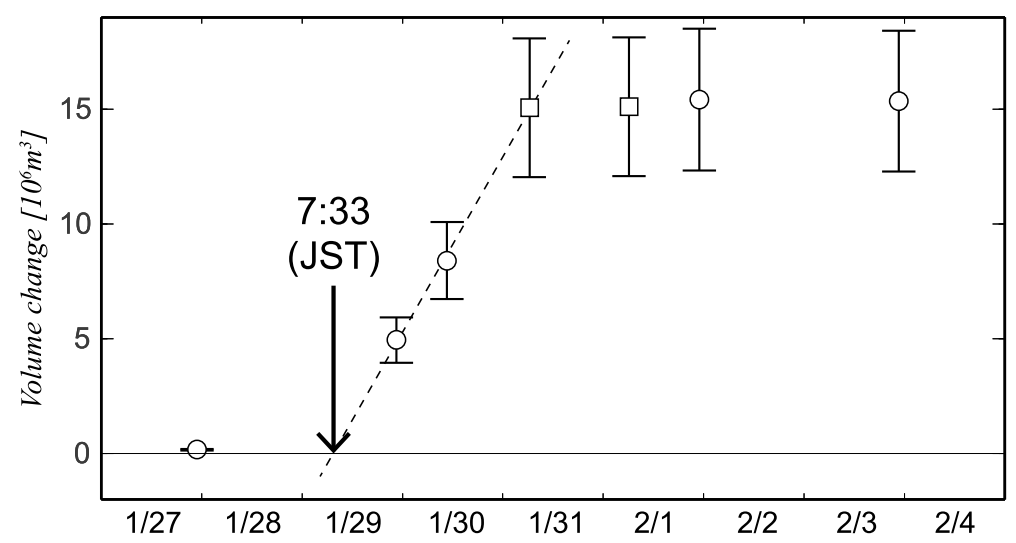

Fig. 9. Estimated time-series of lava volume. Open circles and open squares were estimated from PALSAR and TerraSAR-X images, respectively. The error bar indicates $20 \%$ uncertainty of estimated volume. The dashed line indicates the lava effusion rate of $88.7 \mathrm{~m}^{3} / \mathrm{sec}$ estimated from volumes on January 29,30 , and 31 . The arrow indicates the $\mathrm{x}$-intercept in the estimation of the lava effusion rate.

uary 29 at 7:33 (JST), and its time corresponds to the time when continuous tilt change began (Fig. 2). The observation time of the TerraSAR-X image of January 31 was just before its continuous tilt change stopped, and the volume change was insignificant thereafter. This consistency indicates the significance of estimated volume time-series and implies a close relationship between lava effusion and tilt change in this period. Kozono et al. (2013) addressed this relationship, and therefore we do not address it further in this paper. The PALSAR image of January 27 was observed earlier than the time of the $\mathrm{x}$-intercept. Even if the convex shape in that image is a lava dome, it means that the lava did not grow significantly until the time of the $\mathrm{x}$-intercept.
Needless to say, the possibility that the convex shape is not lava still remains.

Next, we discuss the lava viscosity based on the estimated growth of its configuration. Huppert et al. (1982) solved the theoretical growth of a lava dome. Its radius $r_{N}$ when lava is extruded on a flat area at a constant rate can be expressed by

$$
r_{N}=0.715\left(g \Delta \rho Q^{3} / 3 v\right)^{1 / 8} t^{1 / 2},
$$

where $t$ is time from the effusion start, $g$ is gravity acceleration, $\Delta \rho$ is the density difference between lava and air, $Q$ is the lava effusion rate, and $v$ is the lava viscosity. In this study, we estimated the lava effusion rate $Q$ and the area 


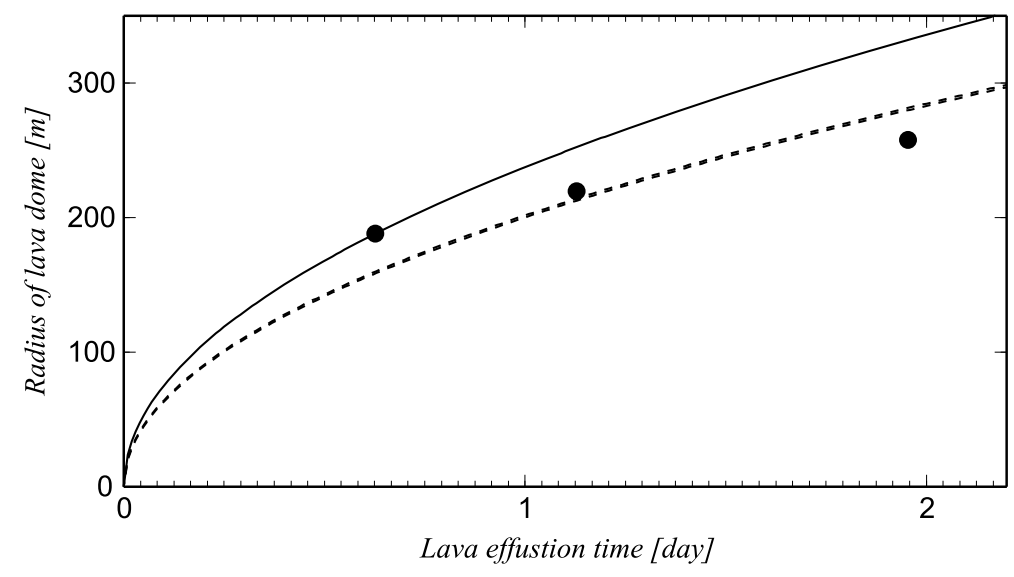

Fig. 10. Estimated time-series of lava radius. The dashed curve was estimated by adjusting the Eq. (2) to radii of January 29,30 , and 31 . The solid curve was estimated from only the radius of January 29.

covered by lava $S$ (Table 2). For simplicity, the radius of lava $r_{N}$ was estimated by $(S / \pi)^{1 / 2}$, assuming its configuration to be a circle. The density difference between lava and air $\Delta \rho$ can be assumed to be the lava density, which is $2500 \mathrm{~kg} / \mathrm{m}^{3}$, the typical value for andesite lava. The lava viscosity can then be estimated based on these parameters. Adjusting Eq. (2) to radii of January 29, 30, and 31 by leastsquare analysis (dashed curve in Fig. 10), a viscosity of 8.4 $\mathrm{GPa} \cdot \mathrm{s}$ was obtained. However, the fit does not seem to be good, possibly due to the unreliable assumption that lava extruded on a flat area. Actually, the pre-eruption topography of the crater is bowl-shaped, and extension of the radius must have been blocked by the slope. Growth of the lava radius decreased with increasing size of lava relative to the fitted curve. Furthermore a crust which has been formed by cooling of the lava surface may have also blocked extension of the radius. If this interpretation is true, the viscosity of $2.1 \mathrm{GPa} \cdot \mathrm{s}$ estimated from only the area of January 29 should be close to the actual value (solid curve in Fig. 10). Since blocking effects may also be included in its result, the actual viscosity may be lower.

Kozono and Koyaguchi (2009) estimated the viscosities of lava flows and lava domes for some eruption events. The viscosities of lava domes are more than $10 \mathrm{GPa} \cdot \mathrm{s}$, significantly greater than the result in this study. The viscosity of the 1914 lava flow of the Sakurajima volcano located $40 \mathrm{~km}$ south-southwest of the Kirishima volcano was estimated to be 0.5 to $11.2 \mathrm{GPa} \cdot \mathrm{s}$. Ishihara et al. (1985) estimated its lava effusion rate as 29 to $1190 \mathrm{~m}^{3} / \mathrm{sec}$. The viscosity and lava effusion rate estimated in this study are included in their ranges. The lava that appeared in the Kirishima eruption had the potential to form a lava flow if it appeared outside the crater.

\section{Summary}

In this paper, we discussed the temporal variations of the Shinmoe-dake crater in the 2011 eruption observed in SAR images. Furthermore, we developed a method that roughly estimates the topography using one SAR image and found that the lava dome in the crater rapidly grew from January 29 until 31 at a constant effusion rate. The lava volume estimated from the TerraSAR-X image on February 1 was con- sistent with that estimated by airborne SAR observations on the same day within $20 \%$ of its volume. Based on the approximated growth of the lava dome, we estimated that the viscosity of lava was less than $2.1 \mathrm{GPa} \cdot \mathrm{s}$. This result indicates that the lava had the potential to form a lava flow if it appeared outside the crater. Moreover, foreshortening distortion could be corrected using the estimated topography, and it is suggested that lava extruded from the area around the crater lake.

Since the method developed in this study estimates parameters semi-quantitatively, the uncertainty of the result may be large. Although we tried to estimate topography without other information in this analysis, some information may have been considered unconsciously. Conversely, higher accuracy may be obtained by applying this method with additional information, such as an aerial photographs.

Acknowledgments. We are grateful to Dr. Charles Wicks and an anonymous reviewer for their fruitful comments. This study was partially supported by the Special Coordination Funds for Promoting Science and Technology from MEXT, "Urgent study on the 2011 eruption of Kirishima-Shinmoe-dake volcano", and the ERI cooperative research program. We used PALSAR data that are shared within the PALSAR Interferometry Consortium to Study our Evolving Land surface (PIXEL) in this study. The data were provided by JAXA under a cooperative research contract with ERI, the University of Tokyo. Emergent PALSAR observations were carried out based on observation proposals from the Volcano Working Group, a special project for the evaluating ALOS for disaster mitigation, coordinated by JMA and JAXA. Part of the data used was provided based on the research of the Volcano Working Group. The original PALSAR data are owned by JAXA and the Ministry of Economy, Trade and Industry. The original TerraSAR-X data are owned by Infoterra $\mathrm{GmbH}$ and provided by Pasco Corporation. The original RADARSAT- 2 data are owned by MDA, and provided by ImageONE Co., Ltd. GEONET data and $10 \mathrm{~m}$-mesh DEM published by GSI were used in this study.

\section{References}

Huppert, H. E., J. B. Shepherd, H. Sigurdsson, and R. S. J. Sparks, On lava dome growth, with application to the 1979 lava extrusion of the Soufriere of St. Vincent, J. Volcanol. Geotherm. Res., 14, 199-222, 1982.

Imura, R. and T. Kobayashi, Eruptions of Shinmoedake Volcano, Kirishima Volcano Group, in the last 300 years, Kazan, 36, 135-148, 1991 (in Japanese with English abstract).

Ishihara, K., M. Iguchi, and K. Kamo, Lava flows at Sakurajima volcano 
(II) - Numerical simulation of the 1914 lava flows on the western side of Sakurajima-, Disast. Prev. Res. Inst. Annuals, 28(B-1), 1-11, 1985 (in Japanese with English abstract).

Kozono, T. and T. Koyaguchi, Effects of relative motion between gas and liquid on 1-dimensional steady flow in silicic volcanic conduits: 2 . Origin of diversity of eruption styles, J. Volcanol. Geotherm. Res., 180, 37-49, 2009.

Kozono, T., H. Ueda, T. Ozawa, E. Fujita, T. Koyaguchi, A. Tomiya, and Y. Suzuki, Magma discharge variations during the 2011 eruptions of Shinmoe-dake volcano, Japan, revealded by geodetic and satellite observations, Bull. Volcanol., 75:695, doi:10.1007/s00445-013-0695-4, 2013.

Leberl, F. W., G. Domik, J. Raggam, and M. Kobrick, Radar stereomapping techniques and application to SIR-B images of Mt. Shasta, IEEE Trans. Geosci. Remote Sensing, 24, 473-481, 1986.

Lemoine, F. G., D. Smith, R. Smith, L. Kunz, E. Pavlis, N. Pavlis, S. Klosko, M. Chinn, M. Torrence, R. Williamson, C. Cox, K. Rachlin, Y. Wang, S. Kenyon, R. Salman, R. Trimmer, R. Rapp, and S. Nerem, The development of the NASA GSFC and NIMA Joint Geopotential Model, in Gravity, Geoid, and Marine Geodesy, IAG Symp., 117, edited by J. Segawa et al., pp. 461-469, Springer, New York, 1997.

Li, F. K. and R. M. Goldstein, Studies of multibaseline spaceborne interferometric synthetic aperture radars, IEEE Trans. Geosci. Remote Sensing, 28, 88-97, 1990.

Miyagi, Y., The eruption activity at Shinmoedake volcano revealed by TerraSAR-X (DLR), Rep. Coord. Comm. Predict. Volcan. Erup., 110, 198-203, 2013 (in Japanese).

Miyagi, Y., T. Ozawa, and Y. Kohno, Crustal deformation associated with the 2011 Eruption of Shinmoe-dake in Kirishima Volcano Group,
Southwestern Japan, detected by DInSAR and GPS measurements, Kazan, 2013 (in Japanese with English abstract) (accepted).

Nakada, S. and Joint Observation Team of Kirishima Volcano, Outline and eruption scenario of the 2011 eruption of Kirishima Volcano, Japan Geoscience Union Meeting 2011, SVC050-01, 2011.

Shimbori, T. and K. Fukui, Time variation of the eruption cloud echo height from Shinmoe-dake volcano in 2011 observed by Tanegashgima and Fukuoka weather radars. Part II, Rep. Coord. Comm. Predict. Volcan. Erup., 109, 173-178, 2012 (in Japanese).

Shimono, T., H. Minami, Y. Nishii, H. Ohno, and K. Watanabe, Observation of volcanic crater of Mt. Kirishima (Shinmoedake) by Airborne SAR, J. GSI, 121, 189-194, 2011 (in Japanese).

Ueda, H., T. Kozono, E. Fujita, Y. Kohno, M. Nagai, Y. Miyagi, and T. Tanada, Crustal deformation associated with the 2011 Shinmoe-dake eruption as observed by tiltmeters and GPS, Earth Planets Space, 65 , this issue, 517-525, doi:10.5047/eps.2013.03.001, 2013.

Ulaby, F. T., R. K. Moor, and A. K. Fung, Microwave Remote Sensing, Active and Passive, Radar Remote Sensing and Surface Scattering and Emission Theory, Vol. II., Addison-Wesley Publishing company, 1064 pp., 1982.

Wegmüller, U., Automated terrain corrected SAR geocoding, Proc. 1999 IGARSS, 3, 1712-1714, 1999.

Wegmüller, U. and C. L. Werner, Gamma SAR processor and interferometry software, Proc. the 3rd ERS Symposium, ESA, SP-414, 1686-1692, 1997.

T. Ozawa (e-mail: taku@bosai.go.jp) and T. Kozono 